\title{
CHRONIC MYELOID LEUKEMIA IN PREGNANCY
}

\author{
Rosa Dwi Wahyuni, Agus Alim Abdullah, Mansyur Arif
}

Department of Clinical Pathology, Faculty of Medicine, Hasanuddin University/Wahidin Sudirohusodo Hospital, Makassar, Indonesia. E-mail: rosa.rudy989@gmail.com

\begin{abstract}
Chronic Myeloid Leukemia (CML) is one of leukemias characterized by abnormal growth of myeloid cells in bone marrow. The Philadelphia chromosome is diagnostic parameter for CML. This chromosome is $t(9 ; 22)(q 32 ; q 21)$, a translocation chromosome 9 and 22 relocates a portion of proto-oncogene c-ABL from chromosome 9 to BCR on chromosome 22. Chronic myeloid leukemia consisting of three phases; Chronic, Accelerating and the Blast crisis phase. The clinicaling symptoms of CML are hypercatabolism, splenomegaly, anemia, bruising and sign of Gout. Chronic myeloid leukemia in pregnancy shows a better prognosis than acute leukemia in pregnancy. Chronic myeloid leukemia has the risk of leukocytosis which can lead to uteroplacental insufficiency giving rise to various consequences: fetal growth retardation and perinatal mortality. Moreover, the therapy of CML should be carefully administered considering the fetal effects. Both sexes have the same risk, mostly in the range of 40 to 60 years old. In this case report, a 38-year-old pregnant female (G1P0A0) with 37 weeks of gestational age was diagnosed as CML on August 2013 and was treated with $500 \mathrm{mg}$ of Cytodrox/Hydroxyurea twice to three times a day until January 2014. Laboratory evaluation on November 10th, 2014, showed leucocytes $449500 / \mu \mathrm{L}$, erythrocytes $2.58 .106 / \mu \mathrm{L}$, hemoglobin $8.0 \mathrm{~g} / \mathrm{dL}$, thrombocytes $437,000 / \mu \mathrm{L}$ and hematocrit $23 \%$. The peripheral blood smear showed normocytic normochromic erythrocytes, anisocytosis, ovalocytes, significantly increased leucocyte count, predominance polymorphonuclear series, all maturation series of myelocytes, $7 \%$ myeloblast, normal thrombocyte count and morphology. Based on these evaluations, the patient was diagnosed as CML. The evaluation of Neutrophil Alkaline Phosphatase (NAP) scored 1.
\end{abstract}

Key words: Chronic myelomonocytic leukemia, pregnancy, bone marrow aspiration, neutrophil alkaline phosphatase score

\section{INTRODUCTION}

Chronic Myeloid Leukemia (CML) is a form of leukemia characterized by the increased and irregular growth of myeloid cells in the bone marrow. ${ }^{1}$ Chronic myeloid leukemia is a clonal disorder of pluripotent stem cells. Chronic myeloid leukemia occupies about $15 \%$ of leukemia and can occur at any age. ${ }^{2}$

A typical Philadelphia chromosome can help to diagnose CML This chromosome is a translocation $\mathrm{t}(9 ; 22)(\mathrm{q} 34 ; \mathrm{q} 11)$ between the chromosome 9 and the chromosome 22 as a result of part of oncogene ABL1 moved to BCR gene in the chromosome 22and part of the chromosome 22 moved to the chromosome 9. The abnormal chromosome 22 is called the Philadelphia chromosome.

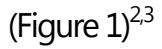

Course of CML disease is divided into three phases i.e.:2-4 Chronic phase: In general, when the first diagnosis is made, the patient is still in a chronic phase. In the chronic phase, patients often complained of enlarged spleen, or felt full in a short time due to the pressure of the spleen against the gaster. The length of the chronic phase varies and depends on how early the disease has been diagnosed and the therapy used at that time. Without adequate treatment, the condition may progress into the acceleration. Acceleration phase: The leukocyte count becomes difficult and additional cytogenic abnormalities may arise. Diagnostic criteria in which the chronic phase is transformed into an acceleration phase are variated.
The most used criteria is the criteria used in MD Anderson Cancer Center and the criteria from WHO. The WHO criteria to diagnose CML, are: 10-19\% myeloblasts in the blood and or in the bone marrow, $>20 \%$ basophils in the blood and/or bone marrow. Platelets are less than 100,000, not responsive to therapy.

Cytogenic evolution in the presence of abnormal genes is the Philadelphia chromosome, there is splenomegaly or increased leukocyte count. Patients are suspected to be in the acceleration phase based on the signs already mentioned. Acceleration phase is very significant because the changes to blast crisis are close to each other. Blast crisis phase: The blast crisis is the final phase of $\mathrm{CML}$ and the symptoms are similar to acute leukemia, with rapid progression and in a short duration. The blast crisis is diagnosed when the CML patients have these following signs: > 20\% blasts in the blood and or bone marrow, a large group of blast cells on bone marrow biopsy can be found.

The disease occurs in both sexes, mostly between the ages of 40 and 60 years. Clinical symptoms in CML are..$^{2,5}$ Hypercatabolic symptom: weight loss, weakness, anorexia, night sweats; Splenomegaly is almost constant and often massive. In some patients, the enlargement of the spleen is associated with discomfort, pain or indigestion; Anemia features may include pallor, spasms, and tachycardia; Bruises, epistaxis, menorrhagia or bleeding from different places due to abnormal platelet function; Gout or renal impairment due 
to hyperuricemia as a result of excess purine breakdown; In more than $50 \%$ of cases, the diagnostic is confirmed by chance at routine blood tests.

Chronic Myeloid Leukemia in pregnancy has a better prognosis than acute leukemia in pregnancy, although in CML there is still a risk of leukocytosis that can lead to uteroplacental insufficiency that will increase conditions such as impaired fetal growth, premature birth, and increased perinatal mortality. Besides, therapy in CML should be monitored because it can affect the health of the fetus. ${ }^{4,7}$

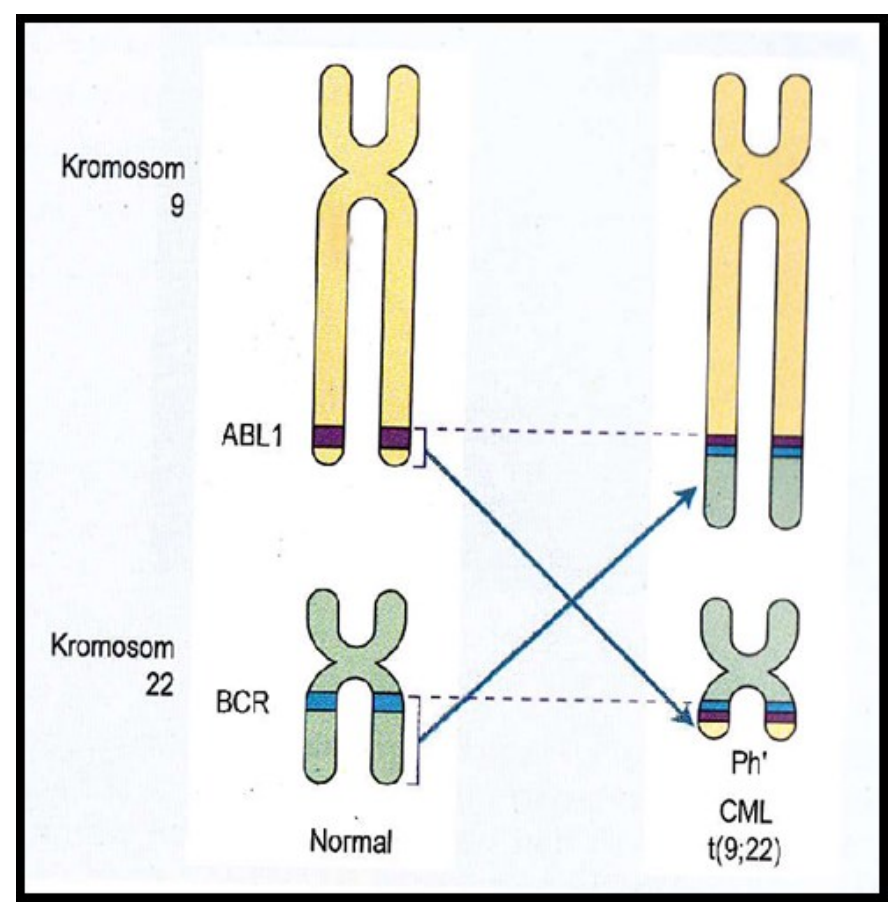

Figure 1. Philadelphia chromosome ${ }^{4}$

Response to treatment can be identified based on several criteria, including hematologic criteria. If leucocytes are less than $9,000 / \mathrm{mm}^{3}$, no splenomegaly and normal morphology, then this indicates the overall treatment response (complete response). When the leukocytes are less than $20,000 / \mathrm{mm}^{3}$ and splenomegaly then it is a partial treatment response (partial response). The treatment fails if the leukocytes are more than $20,000 / \mathrm{mm}^{3}$ and splenomegaly. ${ }^{1,8}$

The most common manifestations of the acceleration phase are splenomegaly and thrombocytosis. Splenectomy can be performed for massive splenomegaly. Thrombocytosis may be difficult to control because thrombocytosis is sometimes resistant to Imatinib and often resistant to Hydroxycarbamide. ${ }^{2}$

\section{CASE}

A 38-year-old female with gravida G1P0A0 37 weeks came to Obgyn in the Wahidin Sudirohusodo Hospital (RSWS) Makassar to check her fetus. In August 2013 the patient was diagnosed with CML and was given Cytodrox, consumed until January 2014 (Cytodrox/Hydroxyurea 500 mg 2-3x1) but irregularly and had been stopped itself because the patient felt dizzy. On physical examination there was an anemic impression, blood pressure: $100 / 70 \mathrm{mmHg}$, pulse: $80 \mathrm{x} /$ minute, temperature: $36.7^{\circ} \mathrm{C}$, there was no wheezing in the lungs. The height of uterine fundus was $24 \mathrm{~cm}$, abdominal circumference: $79 \mathrm{~cm}$, estimated fetal weight: 1,896 grams, lien schuffner 2, liver was not palpable. USG examination: sole gravida, estimated gestational age 34-35 weeks.

Laboratory tests on November $10^{\text {th }}, 2014$ showed the results of leukocyte count $449,500 / \mu \mathrm{L}$, erythrocyte count $2.58 .10^{6} / \mu \mathrm{L}$, hemoglobin level $8.0 \mathrm{~g} / \mathrm{dL}$, thrombocyte count 437,000/ $\mu \mathrm{L}$, hematocrit 23\%. Assessment of peripheral blood images shows normocytic normochromic enythrocytic feature, anisocytosis, ovalocytes, leukocytosis, a dominance of polymorphonuclear series (PMN), all stages of matured myeloid series were found, myeloblast 7\%, enough platelets, and normal morphology, thus summing up the suspicious impression of CML. The results of a random blood glucose test, renal function tests, liver function tests, electrolytes were all within normal limits.

Score examination of Neutrophil Alkaline Phosphatase (NAP) was conducted at the Hassanudin University, Makassar Education Hospital on November $11^{\text {th }}, 2014$ (Figure 2).

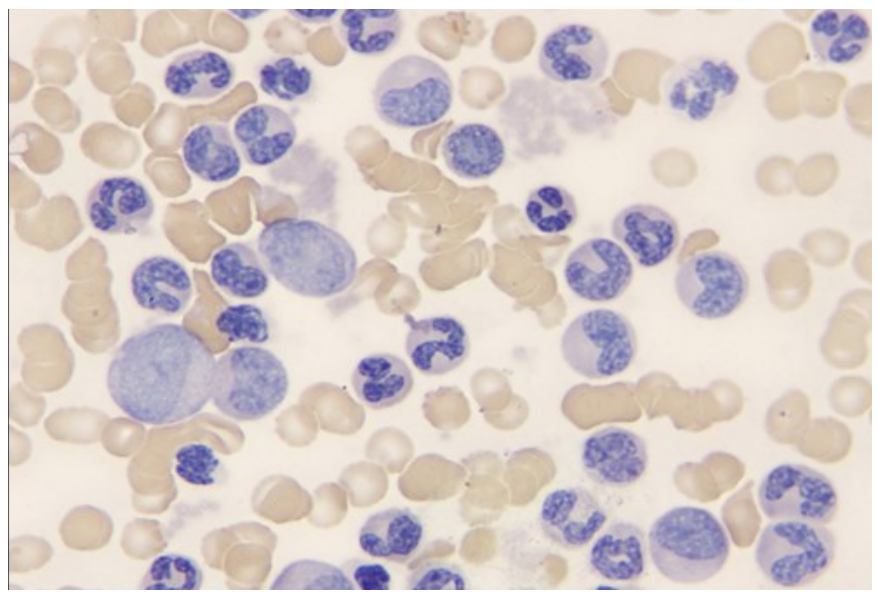

Figure 2. Neutrophil alkaline phosphatase score examination in patient with a score of 1: one-to-one or few granules in the cytoplasm

The overall NAP score was obtained by assessing the color intensity of 100 neutrophils, with each neutrophil was scored on 0 - 5 scale as follows:

0 : Negative, no granules or reactions

1: One-to-one or few granules in the cytoplasm

2: Some granules in groups

3: Granules are spread evenly

4: Cell is full of granules but the nucleus is still visible

5: Maximum number of granules, the nucleus is no longer visible

Laboratory examination was done again on November 27,2014 , with the result of leukocyte count $444,500 / \mu \mathrm{L}$, erythrocytes $2.73 .106 / \mu \mathrm{L}$, hemoglobin $8.3 \mathrm{~g} / \mathrm{dL}$, platelets $456,000 / \mu \mathrm{L}$, hematocrit $25 \%$, lymphocytes 3.2.103, 
The patient was admitted to hospital on December 3, 2014 sent from Obgyn RSWS Outpatient with laboratory results: leukocyte count $427,000 / \mu \mathrm{L}$, erythrocyte count $2.95 .10^{6} / \mu \mathrm{L}$, hemoglobin levels $9.5 \mathrm{~g} / \mathrm{dL}$, platelet count $459,000 / \mu \mathrm{L}$, hematocrit $34 \%$, lymphocyte count $23.9 .10^{3}$, monocyte count 20.9.10 , basophil count $43.1 .10^{3}$. USG result: gravid sole living, head presentation, left back, placenta in the posterior corpus uteri, grade III, amnion fluid impression was less. Diagnosis of admission in hospital G1P0A0 gestational age 37 weeks, CML, oligohydramnion, fetal growth was inhibited. Physiological delivery, male infant, BW: 2,015 grams, LB: $44 \mathrm{~cm}$.

\section{DISCUSSION}

The incidence of CML is between 1-2 cases per 100,000 people per year, with a ratio between males and females 2: 1 . The median age of CML is $45-55$ years old, and the incidence will increase with increasing age. ${ }^{1}$ the incidence of leukemia in pregnancy is estimated to range from 1 in 75,000 to 100,000 pregnancies, CML contributes $10 \%$ of leukemia cases in pregnancy. ${ }^{9}$

In CML leukocytosis was found, shift to the left in the differential count and splenomegaly. Often thrombocytosis was found, but rarely erythrocytosis. The clinical course of CML is divided into 3 phases of the disease, there is the chronic phase, the acceleration phase, the blast phase. Diagnosis of CML usually occurs in the chronic phase, with clinical features being asymptomatic in $40 \%$ of patients. ${ }^{2,3}$ Nearly two-thirds of patients in the chronic phase progress to the blast terminal phase of CML through the acceleration phase. Approximately $20-25 \%$ of chronic phase patients continue directly into the blast phase. During the initiation of the chronic phase, there is a massive expansion of the myeloid cell compartment, but its cells still retain its capacity to differentiate, and function normally. ${ }^{4}$ The symptoms that occur in the chronic phase are generally mild and in most asymptomatic patients, newly diagnosed when routine blood sampling is performed. After 4-5 years the disease will develop into an accelerated phase, characterized by immature cells in the blood, resulting in symptoms and reduced response to therapy if it has been given therapy since the chronic phase. The development of the disease from the chronic phase to the acceleration phase is a continuous process, not a single stage. ${ }^{6,4}$ include: ${ }^{1,2}$

Laboratory examinations in $\mathrm{CML}$ patients

A. Routine blood test :

1. Mild anemia becomes progressive in the later stages, normocytic normochromic.

2. Hemoglobin can be less than $10 \mathrm{~g} / \mathrm{dL}$.

3. Peripheral blood view:

1. Leukocytosis $20,000-50,000 / \mathrm{mm}^{3}$ at the beginning then usually more than $100,000 / \mathrm{mm}^{3}$. On examination of peripheral blood smear, found the number of leukocytes is greatly increased.

2. Shows the full spectrum of granulocyte series from myeloblasts to neutrophils, the most prominent component being the neutrophil segment (hypersegmented) and myelocytes, metamyelocytes, promyelocytes and myeloblasts. On examination of the patient peripheral blood smear, showed the dominance of polymorphonuclear series, with all stages of myeloid series maturation, myeloblast $7 \%$ (Figure 3).

The number of basophils in the blood increases.

Platelets can be increased, normal or decreased. In the early phase more often it increases. On examination of peripheral blood smear sufficient platelet counts and normal morphology was found.

NAP scores are always low. Decreased activity of NAP can be found in CML and paroxysmal nocturnal hemoglobinuria whereas increased NAP activity is found in infections (leukemoid reactions), growth factor therapy, myeloproliferative disorders (polycythemia vera and primary myelofibrosis), stress, drugs (corticosteroids), oral contraceptives, pregnancy, postpartum. ${ }^{10}$ In NAP patients the scores were examined (Figure 2) with NAP score 1, so it was known that $C M L$ rather than infection reaction caused leukocytosis occurring in this patients, because if caused by infection the NAP score would increase.

Bone marrow features $2,4,6$

Hypercellular with dominant granulocyte system. The picture is similar to a peripheral blood smear. Shows the full spectrum of the myeloid series, with the most components of neutrophils and myelocytes. Blast cells are less than $30 \%$. Megakaryocytes in the chronic phase are normal or increased (Figure 4).

Cytogenics: Philadelphia (Ph1) chromosomes in 95\% of cases can be found.

Vitamin B12 serum and B12 binding capacity increased.

Uric acid level increased.

Polymerase Chain Reaction (PCR) examination can detect the presence of chimeric bcr-abl protein in $99 \%$ of cases. series maturation, myeloblast $7 \%$ (Figure 3).

3. The number of basophils in the blood increases.

4. Platelets can be increased, normal or decreased. In the early phase more often it increases. On examination of peripheral blood smear sufficient platelet counts and normal morphology was found.

5. NAP scores are always low. Decreased activity of NAP can be found in CML and paroxysmal nocturnal hemoglobinuria whereas increased NAP activity is found in infections (leukemoid reactions), growth factor therapy, myeloproliferative disorders 
(polycythemia vera and primary myelofibrosis), stress, drugs (corticosteroids), oral contraceptives, pregnancy, postpartum.10 In NAP patients the scores were examined (Figure 2) with NAP score 1, so it was known that $\mathrm{CML}$ rather than infection reaction caused leukocytosis occurring in this patients, because if caused by infection the NAP score would increase.

b. Bone marrow features ${ }^{2,4,6}$

1. Hypercellular with dominant granulocyte system. The picture is similar to a peripheral blood smear. Shows the full spectrum of the myeloid series, with the most components of neutrophils and myelocytes. Blast cells are less than $30 \%$. Megakaryocytes in the chronic phase are normal or increased (Figure 4).

2. Philadelphia (Ph1) chromosomes in $95 \%$ of cases can be found.

c. Vitamin B12 serum and B12 binding capacity increased.

d. Uric acid level increased.

e. Polymerase Chain Reaction (PCR) examination can detect the presence of chimeric bcr-abl protein in $99 \%$ of cases.
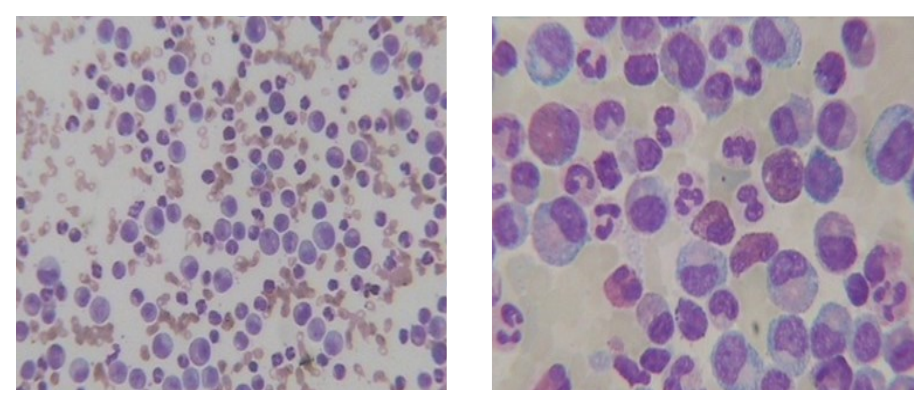

Figure 3. CML peripheral blood view; increased levels of leukocytes, eosinophils and myeloid series such as netrophil segment, neutrophil stab, myelocytes, metamyelocytes and promyelocytes. (1000x magnification, MGG staining).

The goal of CML therapy is to achieve complete remission, both hematological remission (used myelosuppressive drugs), cytogenetic remissions and biomolecular remissions. After hematologic remission is achieved, interferon therapy and/or bone marrow transplant are continued. ${ }^{6,2}$

Busulfan is a palliative drug in CML. At low doses, selective depression is seen in granulopoiesis and thrombopoiesis, at higher doses it can cause depressed erythropoiesis. This drug often causes bone marrow depression so blood tests should be done frequently. Long-term treatment of CML uses a dose of 2-6 mg/day orally and can be increased to $12 \mathrm{mg} /$ day. This drug is given until the leucocyte count reaches $<10,000 / \mathrm{mm}^{3}$, then drug administration is stopped and restarted after the count leukocyte reaches $>50,000 / \mathrm{mm}^{3}$. Side effects caused by busulfan include asthenia, hypotension, nausea, vomiting and weight loss, but it can also cause cataracts, fibrosis, amenorrhea, testicular atrophy. ${ }^{4,7}$

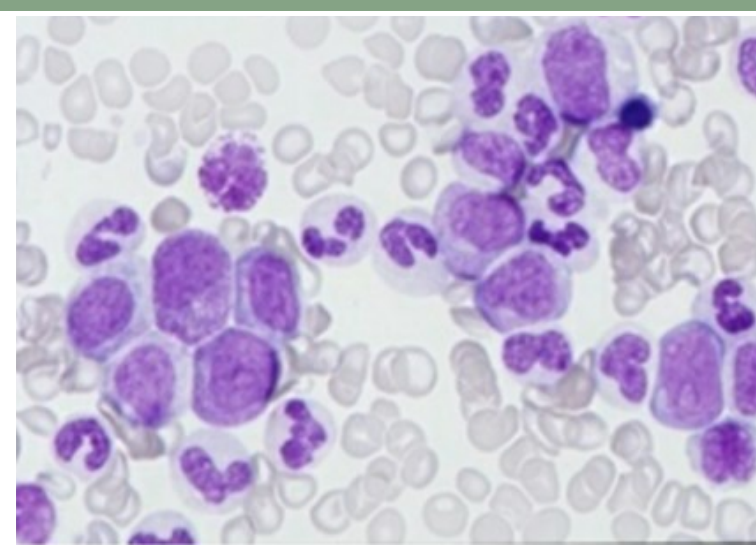

Figure 4. Results of bone marrow aspiration result of CML patients; hypercellular bone marrow features. It shows that there is an increase in eosinophils and megakaryocytes. (1000x magnification, MGG staining)

Management of CML in pregnancy is a dilemma, due to many reports of successful labor in CML patients but the potential teratogenic effects of therapy are of special concern. Some types of therapies that have been used in CML patients during pregnancy include cytotoxic drugs, interferon alpha and leukapheresis. Busulphan and Hydroxyurea inhibit DNA synthesis and may cause abortion, malformations and fetal growth retardation. Chronic myeloid leukemia therapy with Busulphan during pregnancy in three cases was found to cause congenital malformation in the delivered baby. Teratogenic effects are also found in mice given five times the normal dose of Hydroxyurea for humans. ${ }^{11}$ In this patient Hydroxyurea 500mg 2-3x1 was given when diagnosis CML in August 2013-January 2014 but was stopped because the patient felt dizzy, nausea, vomiting. In some places where leukapheresis and interferon are unavailable and termination of pregnancy is unacceptable, the majority of CML patients are treated with Hydroxyurea administration and no fetal side effects are found. ${ }^{12}$ Successful delivery is reported in $\mathrm{CML}$ patients with Hydroxyurea therapy during pregnancy in Malaysia, where Hydroxyurea therapy begins at 27 weeks of gestation and no adverse effects on pregnancy and human fetal growth have not been reported, but there are reports of normal-born infants from mothers with interferon therapy during pregnancy. Leukopharesis therapy has been performed on pregnant patients with CML can be well tolerated by the mother and fetus and no significant side effects were found. Leukopharesis may be considered as CML therapy in the first trimester of pregnancy and may be continued during pregnancy. Due to its low side effects and teratogenic effects, this therapy is an optimal therapy in pregnant patients with CML who can tolerate and respond to this procedure. ${ }^{13}$

Folic acid supplements are needed by pregnant female to prevent babies from leukemia. A new study showed that female who eat more vegetables including 
carrots, long beans, fruits and foods containing protein before pregnancy have a lower risk of developing leukemia in children who are born. Patients are given folic acid during pregnancy at a dose of $4 \mathrm{mg} /$ day. 14

Based on case reports, patients with CML can deliver vaginally on condition that during pregnancy the patient has been treated with either interferon alpha, leukopharesis, or hydroxyurea so that white blood cell counts are well controlled until delivery. In this case, the patient during pregnancy did not receive CML therapy and until delivery the leukocyte count was $427,000 / \mu \mathrm{L}$ and the patient was delivered spontaneously.

\section{LIMITATIONS AND RECOMMENDATION}

The course of the patient's disease is further difficult to know because the patient never came back for check up. Limitations of this report was insufficient 6-month follow-up time because patient no longer came for check up.

Recommendation for this report are: A continuous laboratory examination to monitor the development of therapy is needed; Preferably, in this patient after birth re -BMP should be done to control the course of disease and therapy given.

\section{REFERRENCES}

1. Sudoyo AW, Setiyohadi B, Alwi Idrus, Simadibrata M, Setiati S. Leukemia mieloblastik akut. Dalam: Kurniada J. Buku ajar ilmu penyakit dalam. Jilid II Ed V., Jakarta, Pusat penerbitan departemen ilmu penyakit dalam fakultas kedokteran Universitas Indonesia, 2009; 1234-9.

2. Bakta IM. Leukemia dan penyakit mieloproliferatif. Dalam: Hematologi klinik ringkas, Jakarta, Penerbit buku kedokteran EGC, 2006; 123-5.
1. Bain BJ. Leukemia diagnosis. $4^{\text {th }}$ Ed., United Kingdom, WileyBlackwell, 2010; 16, 27, 90, 160.

2. Hoffbrand AV, Moss PAH. Essential hematology. Dalam: Leukemia myeloid kronis, Ed VI., Jakarta, Penerbit buku kedokteran EGC, 2013; 177-81.

3. Verschuur AC. Acute myelomonocytic leukemia. 2004. Available from: http://www.orphanet/data/ptho/GB/uk-AMLM4.pdf (accessed Nov 26, 2014).

4. Greer JP, Baer MR, Kinney MC. Acute myeloid leukemia in adults. In: Wintrobe' $\mathrm{s}$ clinical hematology. $11^{\text {th }}$ Ed., Vol.2, Philadelphia, USA, Lippincott Williams \& Wilkins, 2004; 4228-30.

5. Mehta $A B$, Hoffbrand AV. Acute leukemia. In: Hematology at glance. Oxford, Blackwell Science 2000; 60.

6. Hoffman R, Benz EJ, Silberstein LE, Weitz JI, Jhon A, et al. Hematology basic principles and practice. $3^{\text {rd }}$ Ed., New York, Churchill Livingstone, 2000; 1322-5.

7. Lichtman $M$, Liesveld J. Acute myelogenous leukemia. In: Beutler E, Lichtman M, Coller B, et al. (Eds). William hematology. $6^{\text {th }}$ Ed., New York, McGraw-Hill, 2001; 1047-50.

8. Fitria Rahmah, Abdulah Agus A, Arif Mansyur. Analisis skor neutrophil alkaline phosphatase pada kehamilan dan postpartum. Makassar. 2014; 1-3.

9. Jackson N, Shukri A, Kamaruzaman A. Hydroxyurea treatment for chronic myeloid leukemia during pregnancy. $\mathrm{Br} J$ Haematol. 1993; 85: 203-4.

10. Celiloglu M, Altunyurt S, Undar B. Hydroxyurea treatment for chronic myeloid leukemia during pregnancy. Acta Obstet Gynecol Scand, 2000; 79:803-804.

11. Fadilah SAW, Zailani HA, Keng CS, Norlaila M. Successful treatment of chronic myeloid leukemia during pregnancy with hydroxyurea. Leukemia 2002; 16: 1202-3.

12. Silvers EL, Larson R, Stadtmauer E, Estey E, Lowenberg B, et al. Efficacy and safety of gemtizumab ozogamicin in patiens with CD 33 positive acute myeloid leukemia in first relapse. Journal of Clinical Oncology. 2001; 19(39): 3244-54. 